\title{
Implementing the European Respiratory Roadmap: halfway there?
}

\author{
Nadia Kamel \\ Affiliation: European Respiratory Society, EU Affairs, Brussels, Belgium. \\ Correspondence: Nadia Kamel, EU Office, ERS Office, Rue de Tréves 49-51, Brussels, BE-1040, Belgium. \\ E-mail: nadia.kameldersnet.org
}

0 @ERSpublications

EU rules on trials, BioMed Alliance advocacy and plans for an ERS Research Agency pave the way to realise the Roadmap http://ow.ly/AWHef

Soon 5 years will have passed since the European Respiratory Society (ERS) pronounced its 10-year vision for respiratory medicine with the launch of the European Respiratory Roadmap. With regards to research, the following was stated: "There is a great need to find new, effective ways for collaboration between academic research and innovators, in order to develop better medicines and improved diagnostic methods. A significant problem is the real deficiency of new innovative medicines in the respiratory field, as only nine new therapies have been developed over the past 40 years" [1].

We are swiftly approaching the halfway mark for the 10-year vision set out when the Roadmap was launched, and it is time to assess to what degree policies have changed since then, and identify those areas that merit further efforts by stakeholders to achieve a better environment for better medicines. Two relevant developments have been: 1) the overhaul of the European legislation that governs the conduct of clinical trials in Europe; and 2) our strong involvement in the activities of the Alliance for Biomedical Research in Europe, which recently advocated for radical change in the way the health research priorities are set in the framework of Horizon 2020, the 7-year European Union (EU) Research and Innovation Programme (2014-2020) [2].

\section{Clinical trials regulations}

The 2001/20/EC Clinical Trials Directive (CTD) has been one of the most sharply criticised pieces of pharmaceutical legislation in the history of the EU. Although its original intent was to simplify and harmonise the administrative provisions governing clinical trials in the $\mathrm{EU}$, an inconsistent and heterogeneous implementation of the directive in the different countries led to various delays, legal and bureaucratic hurdles that were seen to stifle innovative international clinical trials in Europe. The CTD was blamed for increasing pan-European trial costs, adding to the burden of red tape and being the cause of a 25\% decrease in applications for clinical trials between 2007 and 2011 in Europe [3].

As a response to these problems, in July 2012, the European Commission proposed replacing the directive with a new EU Clinical Trials Regulation. Following a 2-year legislative process, the new clinical trials regulation was formally signed off on April 16, 2014 and published in the Official Journal on May 27, 2014. It is expected to become effective on June 15, 2016. Two preconditions need to be accomplished by the European Medicines Agency by January 2016: an operational database for clinical trials and a portal for submissions. 6 months after these two components are functional the regulation will come into effect. It is hoped that the approved regulation will restore EU competitiveness in clinical research and the development of new treatments and medicines by reducing bureaucracy. It has been modelled to suit predicted scientific developments that suggest future clinical trials will target more specific patient populations, such as subgroups identified through genomic information [4].

Received: Aug 202014 | Accepted after revision: Aug 222014

Conflict of interest: N. Kamel is an employee of the European Respiratory Society

Copyright @ERS 2014 
ERS is cautiously optimistic that this regulation constitutes a major improvement over the previous CTD, as it introduces a streamlined authorisation procedure with one single application sufficient for conducting clinical trials in several countries [5]. Other measures to cut red tape include simplified reporting procedures, so that researchers no longer have to submit largely identical information on the clinical trial separately to various bodies and member states. A new category for low-risk trials will be subject to a lighter regulatory regime. There is an effort to make research transparent and open to the public. Results will be made publicly accessible in the EU database. Detailed summaries of the study results, including a summary in plain language, are to be submitted within 1 year of termination of the clinical trial. The concept of tacit approval applicable to all assessors aims to minimise the risk of delays in the approval process [6].

\section{BioMed Alliance}

On a more political level, and because the challenges facing clinical research in Europe are common to many medical specialties, the ERS is a founding member of the Alliance for Biomedical Research in Europe (BioMed Alliance). The BioMed Alliance was born out of a realisation that medical societies have an active role to play, and that change can only be achieved by creating stronger links with each other, by adopting common positions and by speaking with a unified voice [7]. In fact, some change is already underway. In the framework of the new EU Research and Innovation Programme Horizon 2020, the BioMed Alliance called for better scientific steering of health research [8].

During the final negotiations crucial support from the lead Member of the European Parliament (Teresa Riera Madurell) helped ensure that the legislative text of Horizon 2020 now makes reference to a Scientific Panel for Health (SPH) [9]. The SPH, which is currently in the process of being established, is a stakeholder platform that, alongside the existing independent advisory boards, will be charged with analysing bottlenecks in the health research innovation system and proposing solutions.

As a next step, the efforts of the BioMed Alliance will now concentrate on developing a strategic outlook for clinical research in Europe, concentrating on a number of new priorities. These priorities include ensuring: that cross- and multidisciplinary collaboration is encouraged; that rather than competing, basic and clinical research is instead integrated into the various disciplines to create true translational research; and that collaboration of academics with industry (e.g. the pharmaceutical and biotechnology industries) is used to achieve more efficient and effective research, and to reduce attrition rates.

\section{Conclusion}

Looking back over the past 5 years, we can say that noteworthy progress has been made in moving towards a better environment for better medicines, both through the adoption of new and improved legislation governing clinical trials in Europe, and through the active commitment and involvement of ERS in the BioMed Alliance.

More generally, looking towards the next 5 years, the overriding aim of ERS will be to continue to support healthcare professionals by providing them with enabling tools to better manage, treat and cure patients with respiratory diseases. In the field of rare pulmonary diseases or for complex comorbid conditions, where the industry is less likely to invest, independent, international, investigator-driven clinical trials will be especially important. The ERS, as a medical society, could facilitate this type of collaboration by acting as a catalyst. In fact, the ERS is currently in the process of exploring options for establishing a Research Agency to address clinical research needs in well-defined areas of respiratory medicine [10].

The creation of an ERS Research Agency could be a game changer and constitute a very real and significant manifestation of the vision that was set out 5 years ago in the European Respiratory Roadmap. With continued and sustained efforts, ERS could act as an enabling force to help bring together patients, clinicians, researchers in pan-European collaborations that could, ultimately, bring advances and change to both medical practice and the prevention, management and treatment of lung and respiratory diseases.

\section{References}

Decramer M, Sibille Y, eds. European Respiratory Roadmap. Sheffield, European Respiratory Society, 2011.

Mansell P. Biomed Alliance welcomes Horizon 2020 health panel. PharmaTimes, Clinical News. www.pharmatimes. com/article/13-12-03/Biomed_Alliance_welcomes_Horizon_2020_health_panel.aspx. Date last accessed: August 20, 2014 Date last updated: December 03, 2013.

3 European Commission. Proposal for a regulation of the European parliament and of the council on clinical trials on medicinal products for human use, and repealing Directive 2001/20/EC. Brussels, European Commission, 2012. http://ec.europa.eu/health/files/clinicaltrials/2012_07/proposal/2012_07_proposal_en.pdf Date last accessed: August 20, 2014. Date last updated: July 17, 2012.

4 European Cancer Organisation. EJC News: Summer 2014. Two cheers for the new Clinical Trials Regulation. www. ecco-org.eu/Global/News/Latest-News/2014/06/EJC-News-Summer-2014 Date last accessed: August 20, 2014. Date last updated: June 19, 2014. 
5 Official Journal of the European Union. Regulation (EU) No 536/2014 of the European Parliament and of the Council of 16 April 2014 on clinical trials on medicinal products for human use, and repealing Directive 2001/20/ EC. OJ L 158, 27.5.2014, p. 1-76. http://eur-lex.europa.eu/legal-content/EN/TXT/?uri=uriserv:OJ.L_.2014.158.01. 0001.01.ENG Date last accessed: August 20, 2014. Date last updated: April 16, 2014.

6 European Commission. MEMO/14/245. Q\&A: new rules for clinical trials conducted in the EU. http://europa.eu/ rapid/press-release_MEMO-14-254_en.htm Date last accessed: August 20, 2014. Date last updated: April 2, 2014.

7 Nicod LP, Kamel N, Ward B, et al. ERS is founding member of a new Alliance for Biomedical Research in Europe. Eur Respir J 2011; 38: 237-238.

8 BioMed Alliance. Panel Press Release. A leap forward for health research in Europe: top scientists to have more say in EU-funded research agenda. Brussels, BioMed Alliance, 2013. www.biomedeurope.org/images/pdf/news/ BioMed_Press_release_FINALversion_NoEdits.pdf Date last accessed: August 20, 2014. Date last updated: November 20, 2013.

9 European Commission. Research and Innovation. Terms of reference for the Horizon 2020 societal challenge 1 scientific panel for health. Version 1. http://ec.europa.eu/research/health/pdf/mandate-of-the-sph-18062014_en.pdf Date last accessed: 20 August, 2014. Date last updated: June 18, 2014

10 Migliori GB, Rabe KF, Bel E, et al. The European Respiratory Society plans its future: the 2013-2018 strategic plan. Eur Respir J 2014; 43: 927-932. 